\title{
Spectral density estimation of European airlines load factors for Europe-Middle East and Europe-Far East flights
}

\author{
Yohannes Yebabe Tesfay • Per Bjarte Solibakke
}

Received: 18 July 2014 / Accepted: 3 March 2015 /Published online: 16 April 2015

(C) The Author(s) 2015. This article is published with open access at SpringerLink.com

\begin{abstract}
Purpose In the airline industry the term load factor is defined as the percentage of seats filled by revenue passengers. The load factor is a metric that measures the airline's capacity and demand management. This paper aimed to identify serial and periodic autocorrelation on the load factors of the Europe-Mid East and Europe-Far East airline flights. Identifying the autocorrelation structure is helpful to develop the best fitted forecasting model of the load factors.

Methods The paper applies spectral density estimation to investigate the structure of serial and periodic autocorrelation on the load factors. Then the paper applied multivariate trend model to develop a forecasting model of the load factors of the regional flights. The multivariate trend model is fitted using the Prais-Winsten recursive autoregression methodology.

Results The primary analysis of the study identified that the airlines have better a demand than capacity management system for both the Europe-Mid East and Europe-Far East flights. The spectral density estimates showed that the load factors have both periodic and serial correlations for both regional flights. Therefore, in order to control the periodic autocorrelation, we introduce transcendental time functions as predictors of the load factor in the multivariate trend model. Finally, we build realistic and robust forecasting model of the load factors of the Europe-Mid East and Europe-Far East flights.

Conclusions The econometric estimation results confirm that the load factors of the Europe-Mid East and Europe-Far East
\end{abstract}

This article is part of the Topical Collection on Accessibility and Policy Making

Y. Y. Tesfay $(\bowtie) \cdot$ P. B. Solibakke

Molde University College, Britveien 2, Kvam, 6402 Molde, Norway

e-mail: yohannesyebebabe@gmail.com

P. B. Solibakke

e-mail: per.b.solibakke@hiMolde.no flights are both seasonal and differ between flights. The analysis implies that the load factor is still far from stable and stabilizing policies by airlines has so far not been successful. The AEA may therefore continuously focus on the stabilization and the improvement of the load in the industry.

Keywords Airlines $\cdot$ Load factor $\cdot$ Spectral density estimation $\cdot$ Multivariate trend analysis

\section{Introduction}

The yield, revenue per unit of output sold, is a highly significant metric in the airline industry. By definition, it is only the mathematical outcome of two even more fundamental metrics: output sold and revenue earned. For more than five decades the yields across the industry as a whole has been in decline. These price declines explain a significant portion of the traffic growth throughout the period [33]. Broadly speaking, the yields will soften when (1) traffic growth is flat or insufficient to absorb output growth, (2) intense competition lower prices, and yields will harden when (2a) load factors are already high and output is growing slower than traffic, (2b) traffic growth is outstripping growth in output and (3) lower competition keeps prices unchanged. The fact that traffic, load factor, and revenue all will be affected by these type of adjustments, illustrates how intimately connected the variables are-all within the context of available output $[37,38]$.

This paper's main variable of interest is the airline industry load factor. The load factor measures the percentage of an airline's output that has been sold to paying passengers. Hence, the load factor is a measure of the extent to which supply and demand are balanced at prevailing prices. The achieved load factors for the industry as a whole conceal marked variations between different type of airliners, with regional carriers at the lower end of the spectrum and charter 
airlines generally achieving higher load factors than scheduled carriers [8]. The average load factors for individual airline enterprises masks variations between different markets and cabins. Economy cabins achieving higher load factors because customers tend to book further in advance and expect lower levels of seat accessibility than for premium cabins. The average load factors in the airline industry also conceal pronounced daily, weekly and, in particular, seasonal variations.

There are at least six load factors drivers in the airline industry. The first driver is the industry's output decisions relative to demand growth. The output growth must be brought into alignment with demand growth. The second driver is pricing. Fare reductions generally stimulate demand. Load factors are affected depending upon capacity decisions. The third driver is the traffic mix. Historically, the higher the proportion of business travellers carried by an airline, the lower the average seat factor. That is, the random element in demand for business travels (highly volatile demand) suggests a lower average load factor in business and first class cabins [31]. The fourth driver is refund policies. A carrier taking nonrefundable payment at the time of reservation is likely to have relatively few no-shows and a relatively higher seat factor than carriers selling a high portion of fully flexible tickets. The fifth driver is commercial success. A success of product design, promotions, marketing communications, distributions, and service delivery will influence load factors. The sixth driver is revenue management. The effectiveness of revenue management systems (RMS) will influence load factors. The RMS capabilities, specifically the refinement of demand forecasting tools, will contribute significantly [30]. Depending on market conditions in the airline industry, there exist a trade-off between load and yield. Unless demand is particularly strong and output growth is under firm control, it is likely that rising yields will be associated with downward pressure on load factors. In contrast, a falling yield tends to be associated with higher load factors. The trade-off suggests that airline carriers will generally want to arrive at a capacity, which targets a load factor balances between the costs of turning passengers away and the costs of meeting all peak demand and oversupplying the market ("double-edged sword"). In general, therefore, from an operational perspective it is easier to manage an airline when load factors are at $64 \%$ than when they are at $84 \%$ [9]. The size of the load factor is therefore a measure of success in the airline industry. However, the success factor is challenged by the fact that demand is volatile and fluctuates in units of single seat-departures in different origin and destination markets. In contrast, the capacity can only be delivered in units of available aircrafts for the particular flight-leg. That is, routes designed to serve the origin and destination markets are broadly fixed in the short run. Furthermore, the necessity to maintain both high flight completion rates, the integrity of network connections, and aircraft/crew assignments, may make it almost impossible for a scheduled passenger carrier to cancel a significant number of its lightly loaded flights [4].

The main objective of this paper is to build econometric models that can capture the variations of load factors for Europe-Middle East and Europe-Far East airline flights. The paper's target population is airlines that are members of the Association of European Airlines (AEA). We use multivariate time series econometric model to analyse the temporal evaluation of load factor. The best well-fitted econometric model may improve the accuracy of forecasting the load factor of these specific flights. However, in order to build the best fitted model for the load factor we are encountered to several challenges. First, we need to evaluate characteristics of available seat kilometre and revenue passenger kilometre on the load factor. Second, we need to have solid knowledge about the autocorrelation structure of the load factor. Classically, we think that the intensity of autocorrelation of time series data diminishes with more distant lags.

However, in reality, the true autocorrelation structure of the load factor has the periodic autocorrelation (i.e., load factor it is highly seasonal). Consequently, we have to identify the structure of both serial and periodic autocorrelations on the load factor. Third, once we identify the autocorrelation structure of the load factor, then we will deal with mechanisms to control it during model fit.

In this study, we advance the classical multivariate trend analyses to control the periodic autocorrelation by expressing the time effect of the load factor as a dynamic (can be linear or nonlinear) function of the parameters [29]. Furthermore, in order to control for the serial autocorrelation we apply PraisWinsten recursive autoregression estimation [34]. Finding the best suitable mathematical relationships of the dynamic time effect of the load factor and controlling serial correlation is therefore the most important task of this study. The best fitted econometric model may bring superior forecasting tools and techniques, and new information to the AEA.

\section{Literature review}

The airline industry plays an essential role in the establishment of today's global economy. According to Doganis [15] the airline industry gives the impression of being both cyclical and strappingly subjective to external dynamics. The international airline industry is complex, dynamic, subject to rapid change, innovation, and marginally profitable. By considering procedures determining tariff levels in an origin-destination market, airline pricing refers to various service facilities and capacities for a set of airline products.

Revenue management is the process of determining the number of seats available at each tariff level. The revenue management of the airline is therefore a function of its tariff strategy and associated load factors. According to Kellner [27] 
the success of the airline is determined by its ability to make unit revenues (i.e., the product of yield and load factor) higher than its unit costs. Therefore, in addition to minimize the unit cost, the important task of the airline manager is to simultaneously maximize the product of yield and load factor [21].

Yield management is the assortment of schemes, strategies and tactics the airline enterprises use to systematically manage demand for their services and products [25]. The fundamental units for yield management are load factors, pricing and cost of the airlines [26]. Passenger load factor (or only load factor) is a measure of the degree of airline passenger carrying capacity. The load factor is a quantity of the extent to which supply and demand are balanced at prevailing prices [18]. In short, load factor is defined as the ratio of the revenue passenger kilometre to available seat kilometre in the given origin destination flight $[14,4]$.

The load factor is a measure of the performance and efficiency of an airline. The airline's load factor directly reflects their competency and performance. The high load factor with appropriate pricing is a condition for the efficient operation of an airline enterprise [40]. Thus, it is enlightening for the performance of the airline to highlight factors that affect the load factors [22].

Generally, operational factors play a significant role in affecting the load factor and therefore capacity. Specifically, operational factors such as distance covered by journey, tourists, codeshare agreement (is an aviation business arrangement where two or more airlines share the same flight) and market concentration HHI index (a commonly accepted measure of market concentration) are among the most important factors that have positive and significant effect on the load factor [32]. Moreover, the GINI index (a measure the degree of price dispersion, or price inequality in the airline of the same flight) is discovered as the main factor that negatively affects the load factor. Other important factors are airport features, performance limitation, flight conditions, seasonality of demand, time of traveller schedule, frequency of flights and dynamic route networks [32, 24].

\section{The data and methodology}

\subsection{The data}

The dataset is obtained from the Association of European Airlines (AEA) and is downloaded from http://www.aea.be/ research/traffic/index.html. The data is collected for the period 1991 to 2013 and contains information about Available Seat-Kilometres (ASK), Revenue PassengerKilometres $(\boldsymbol{R} \boldsymbol{P K})$ and Load factor $(\boldsymbol{L F})$.
Moreover, Europe-Far East $(\boldsymbol{E F})$ is defined as any scheduled flights between Europe and points east of the Middle East region, including Trans-Polar and Trans-Siberian flights. Europe-Middle East $(\boldsymbol{E M})$ is defined as any scheduled Terminating flights between Europe and Bahrain, Iran, Iraq, Israel, Jordan, Kuwait, Lebanon, Oman, Saudi Arabia, Syria, United Arab Emirates, Yemen and the Democratic Republic of Yemen (Available at www.aea.be).

\subsection{Methodology}

\subsubsection{One way analysis of variance (ANOVA)}

One way analysis of variance (ANOVA) is used to see the existences of the main differences of a certain random variables with a single treatment over its levels. The linear statistical model for ANOVA is given as $([6,43]$ :

$$
\begin{aligned}
y_{i j} & =\mu+\alpha_{i}+\varepsilon_{i j}, \quad i=1,2,3, \ldots, a \text { and } j \\
& =1,2,3, \ldots, n
\end{aligned}
$$

where: $\mu$ the grand mean of $y_{i j}, \alpha_{i}$ the $i_{t h}$ level effect on $y_{i j}$ and $\varepsilon_{i j} \sim i i d N\left(0, \sigma^{2}\right)$. The bootstrapping estimation method is applied to estimate the model parameters. Usually the method of estimation of the model parameters is either using ordinal least square (OLS) or generalized least square (GLS) estimators according to the parameters are fixed or random, respectively [17, 11]. Nevertheless, modern econometric methods used bootstrapping to acquire thorough information about the estimated parameters. In this particular case we apply the Bias-Estimation Bootstrap technique. The estimation method gives information about bias of the estimates due to resampling in addition to the estimates of OLS or GLS [13].

\subsubsection{Signal processing}

Signal processing represents a time series as a stochastic sum of harmonic functions of time [20]. Signal processing helps to identify the autocorrelation structure of the time series data. The signal processing stochastic model for stochastic process in discrete time is given as $[23,35]$ :

$y_{t}=\mu_{t}^{*}+\sum_{k}\left[a_{k} \cos \left(2 \pi v_{k} t\right)+b_{k} \sin \left(2 \pi v_{k} t\right)\right]$

Where: $\mu_{t}^{*}$ is the mean of the series at time $t, a_{k}, b_{k}$ (Fourier transformation coefficients of cosine and sine waves) are 
Table 1 Estimates of RPK (in million) and ASK (in million) of the EM and EF flights

\begin{tabular}{|c|c|c|c|c|c|c|c|c|c|c|c|c|}
\hline \multirow[t]{3}{*}{ Flights } & \multicolumn{6}{|c|}{ Estimates of Revenue Passenger Kilometre (RPK in million) } & \multicolumn{6}{|c|}{ Estimates of Available Seat Kilometre (ASK in million) } \\
\hline & \multirow[t]{2}{*}{ Statistic } & \multirow[t]{2}{*}{ Estimates } & \multirow[t]{2}{*}{ Bias } & \multirow[t]{2}{*}{$\begin{array}{l}\text { Std. } \\
\text { Error }\end{array}$} & \multicolumn{2}{|c|}{$\begin{array}{l}95 \% \text { Confidence } \\
\text { Interval }\end{array}$} & \multirow[t]{2}{*}{ Statistic } & \multirow[t]{2}{*}{ Estimates } & \multirow[t]{2}{*}{ Bias } & \multirow[t]{2}{*}{$\begin{array}{l}\text { Std. } \\
\text { Error }\end{array}$} & \multicolumn{2}{|c|}{$\begin{array}{l}95 \% \text { Confidence } \\
\text { Interval }\end{array}$} \\
\hline & & & & & Lower & Upper & & & & & Lower & Upper \\
\hline \multirow[t]{3}{*}{ EM-Flights } & Mean & 1696.92 & 1.863 & 42.52 & 1617.65 & 1784.05 & Mean & 2450.76 & 1.53 & 56.82 & 2333.1 & 2566.78 \\
\hline & Std. Deviation & 729.94 & -2.44 & 24.39 & 680.11 & 774.73 & Std. Deviation & 936.96 & -3.0 & 30.01 & 869.19 & 991.55 \\
\hline & Std. Error Mean & 43.94 & & & & & Std. Error Mean & 56.40 & & & & \\
\hline \multirow[t]{3}{*}{ EF-Flights } & Mean & 9671.81 & -1.77 & 185.7 & 9317.00 & $10,023.0$ & Mean & $12,375.32$ & 10.46 & 193.21 & $12,005.0$ & $12,754.61$ \\
\hline & Std. Deviation & 3059.35 & -6.34 & 95.64 & 2853.89 & 3229.34 & Std. Deviation & 3292.10 & -5.48 & 99.73 & 3089.31 & 3486.857 \\
\hline & Std. Error Mean & 184.15 & & & & & Std. Error Mean & 198.16 & & & & \\
\hline $\begin{array}{r}\text { Estimation } \\
\text { Method }\end{array}$ & \multicolumn{12}{|c|}{ Bootstrap results are based on 1000 bootstrap samples } \\
\hline
\end{tabular}

independent zero mean normal random variables, $v_{k}$ are distinct frequencies.

The mean, variance and covariance of the spectrum of the time series data are derived as follows:

$$
\begin{aligned}
& E\left[y_{t}\right]=E\left[\mu_{t}^{*}\right]+E\left\{\sum_{k}\left[a_{k} \cos \left(2 \pi v_{k} t\right)+b_{k} \sin \left(2 \pi v_{k} t\right)\right]\right\} \\
& E\left[y_{t}\right]=\mu_{t}^{*}+\sum_{k} E\left[a_{k} \cos \left(2 \pi v_{k} t\right)+b_{k} \sin \left(2 \pi v_{k} t\right)\right] \\
& \therefore E\left[y_{t}\right]=\mu_{t}^{*}
\end{aligned}
$$

$$
\begin{aligned}
& \operatorname{Var}\left[y_{t}\right]=E\left\{\left[y_{t}\right]-E\left[y_{t}\right]\right\}^{2} \\
& \operatorname{Var}\left[y_{t}\right]=E\left\{\mu_{t}^{*}+\sum_{k}\left[a_{k} \cos \left(2 \pi v_{k} t\right)+b_{k} \sin \left(2 \pi v_{k} t\right)\right]-\mu_{t}^{*}\right\}^{2} \\
& \therefore \operatorname{Var}\left[y_{t}\right]=E\left\{\sum_{k}\left[a_{k} \cos \left(2 \pi v_{k} t\right)+b_{k} \sin \left(2 \pi v_{k} t\right)\right]\right\}^{2}
\end{aligned}
$$

$\operatorname{Cov}\left[y_{t}, y_{t^{-\tau}}\right]=E\left\{\left(y_{t}-E\left[y_{t}\right]\right)\left(y_{t^{-} \tau}-E\left[y_{t-\tau}\right]\right)\right\}$
S ince $y_{t}-E\left[y_{t}\right]=\sum_{k}\left[a_{k} \cos \left(2 \pi v_{k} t\right)+b_{k} \sin \left(2 \pi v_{k} t\right)\right]$ a n d $y_{t-\tau}-E\left[y_{t-\tau}\right]=\sum_{k}\left[a_{k} \cos \left(2 \pi v_{k} t-\tau\right)+b_{k} \sin \left(2 \pi v_{k} t-\tau\right)\right]$

Therefore, Eq. 5 can be expressed as:

$$
\begin{array}{r}
\operatorname{Cov}\left[y_{t}, y_{t^{-} \tau}\right]=E\left\{\left(\sum_{k}\left[a_{k} \cos \left(2 \pi v_{k} t\right)+b_{k} \sin \left(2 \pi v_{k} t\right)\right]\right)\right\} \\
\left.\left(\sum_{k}\left[a_{k} \cos \left(2 \pi v_{k} t-\tau\right)+b_{k} \sin \left(2 \pi v_{k} t-\tau\right)\right]\right)\right\}
\end{array}
$$

Spectral density is a powerful tool to analyse the nature of the autocorrelation of the time series data in the Fourier space that contains infinite sum of sine and cosine waves of different amplitudes [16, 3]. This creates good prospect to remove the problem of autocorrelation and to choose appropriate an

\begin{tabular}{|c|c|c|c|c|c|c|c|}
\hline \multirow[t]{2}{*}{ Variables } & \multirow[t]{2}{*}{ Comparison of flights } & \multirow[t]{2}{*}{ Mean Difference } & \multirow[t]{2}{*}{ Std. Error Difference } & \multirow[t]{2}{*}{$\mathrm{t}$-cal } & \multirow[t]{2}{*}{ Sig. (2-tailed) } & \multicolumn{2}{|c|}{$\begin{array}{l}95 \% \text { Confidence Interval of mean } \\
\text { difference }\end{array}$} \\
\hline & & & & & & Lower & Upper \\
\hline ASK (in million) & EFVs. EM & 9924.55721 & 212.85460 & 46.625 & 0.001 & 9519.21193 & $10,340.48847$ \\
\hline RPK (in million) & EFVs. EM & 7974.88996 & 186.52502 & 42.755 & 0.001 & 7628.94166 & 8335.74600 \\
\hline LF (in percent) & EFVs. EM & -9.09385 & 0.51125 & 17.787 & 0.001 & 10.09983 & 8.11099 \\
\hline Estimation Method & \multicolumn{7}{|c|}{ Bootstrap results are based on 1000 bootstrap samples } \\
\hline
\end{tabular}
econometric model that capture the possible variations of the time series data. Estimation techniques of spectral density can involve parametric or non-parametric approaches based on time domain or frequency domain analysis. A common parametric technique involves fitting the observations to an autoregressive model. A common non-parametric technique

Table 2 Comparison of ASK, RPK and load factor of EM and EF flights 
Table 3 Prais-Winsten recursive parameter estimation of a linear regression of RPK (in million) in response to ASK (in million)

\begin{tabular}{lllllll}
\hline Predictor & Estimators & $\begin{array}{l}\text { Std. } \\
\text { Error }\end{array}$ & t-cal & Sig. & R Square & $\begin{array}{l}\text { Model } \\
\text { Std. Error }\end{array}$ \\
\hline ASK & 0.776 & 0.013 & 58.912 & 0.0000 & & \\
Constant & -205.356 & 34.683 & -5.921 & 0.0000 & 0.927 & 115.788 \\
\hline
\end{tabular}

is the periodogram. The important advantage of applying the periodogram spectral estimator is determining possible hidden "periodicities" in the time series [36].

\subsubsection{Ljung-Box test}

There are a number of parametric methods that detect autocorrelation. However, the Ljung-Box test is preferable in this case because it simultaneously detects the existence and the order of autocorrelation on the time series data. The LjungBox test procedure is given as [10]: the Null Hypothesis $H_{0}$ : serial correlation equals zero up to order h versus $H_{1}$ : at least one of the serial correlations up to lag $\mathrm{h}$ is nonzero. The test statistic of Ljung-Box is given as:

$Q=n(n+2) \sum_{l-1}^{h} \frac{\widehat{\rho}_{l}^{2}}{n-l}$

where: $n$ is the sample size, $\widehat{\rho}_{l}$ is the sample autocorrelation at lag $l$, and $h$ is the number of lags being tested. The null hypothesis is rejected for $\alpha$ level of significance if $Q>\chi_{l-\alpha, h}^{2}$.

\subsubsection{Multivariate trend analysis}

The aim of the trend analysis is to get the best fitted model to be applied for forecasting the long run behaviour of the series

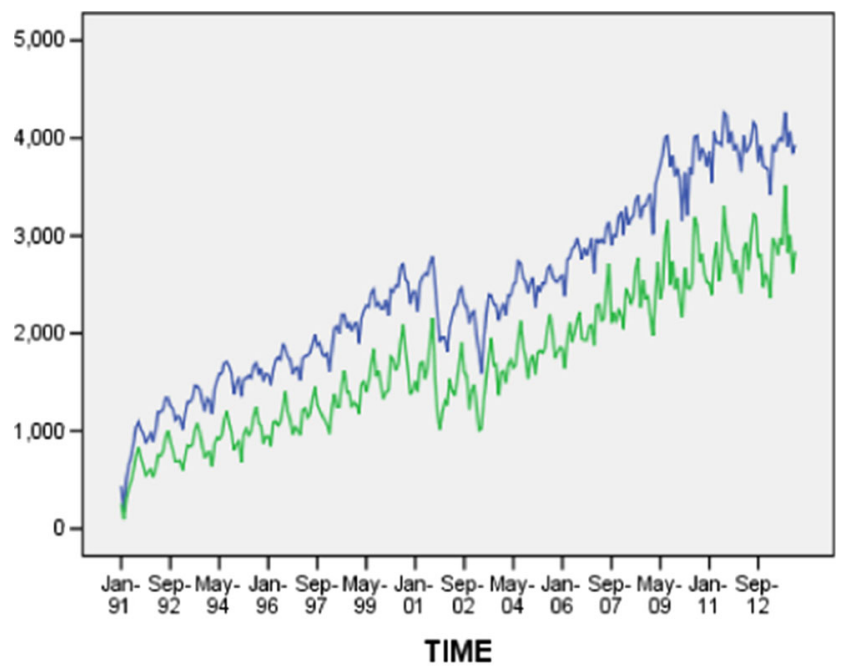

Key: - ASK - RPK

Fig. 1 Time Series Plot of ASK and RPK (in million) of EM flights as a function of time [28]. The general form of multivariate trend analysis is given as $[5,41]$.

$y_{i t}=f_{i}\left(t ; \beta_{i}\right)+\varepsilon_{i t}$

$\varepsilon_{i t}=U\left(\varepsilon_{i t-1}, \varepsilon_{i t-2}, \ldots \varepsilon_{i t-h} ; \rho_{i 1}, \rho_{i 2}, \ldots, \rho_{i h_{i}}\right)+v_{i t}$ and $v_{i t} \sim$ $i i D N\left(0, \sigma_{i v}^{2}\right)$ where: $f_{i}\left(t ; \beta_{i}\right)$ is any real valued function of time " $t$ " and a vector of parameters $\beta_{i}=\left(\beta_{i 0}, \beta_{i 1}, \beta_{i 2}, \ldots, \beta_{i k_{i}}\right), U$ $\left(\varepsilon_{i t-1}, \varepsilon_{i t-2}, \ldots \varepsilon_{i t-h} ; \rho_{i 1}, \rho_{i 2}, \ldots, \rho_{i h_{i}}\right)$ is a linear function of $\varepsilon_{i t-}$ $i j, \rho_{i j}$ and $j=1,2,3, \ldots . h_{i}, \varepsilon_{i t}$ and $v_{i t}$ are random error terms.

To find suitable estimation method of the model parameters, it is necessary to have acquaintance about the mathematical structure of $f_{i}\left(t ; \beta_{i}\right)$. In this case we have two major categories of $f_{i}\left(t ; \beta_{i}\right)$, linear and nonlinear models [41]. If the model is linear then we simply apply the ordinary least square (OLS) estimation method to estimate the model parameters $[39,20]$.

\subsubsection{Steps of controlling serial autocorrelation}

After controlling for periodic autocorrelation by setting the time effects as a function of time, we need to remove the serial correlation. Therefore, the following steps (algorithm) are used to remove serial correlation:

Step 1: First estimate the model fit residuals as [43, 7]:

$\widehat{\varepsilon}_{i t}=y_{i t}-f_{i}\left(t ; \widehat{\beta}_{i}\right)$

Step 2: Determine the structure of autocorrelation. At this step we use the Ljung-Box test of autocorrelation.

Step 3: If we do not reject our null-hypothesis we take the model fit is free from the problem of autocorrelation. Otherwise, we apply the Prais-Winsten estimation recursive estimation to remove serial correlation $[44,19,42,12,1,34]$. The estimated variance covariance matrix is given as:

Table 4 Prais-Winsten recursive parameter estimation of a linear regression of RPK (in million) in response to ASK (in million)

\begin{tabular}{lllllll}
\hline Predictor & Estimators & $\begin{array}{l}\text { Std. } \\
\text { Erro }\end{array}$ & t-cal & Sig. & R Square & $\begin{array}{l}\text { Model Std. } \\
\text { Error }\end{array}$ \\
\hline ASK & 0.914 & 0.015 & 59.147 & 0.0000 & & \\
Constant & -1648.14 & 198.94 & -8.284 & 0.0000 & 0.928 & 378.461 \\
\hline
\end{tabular}




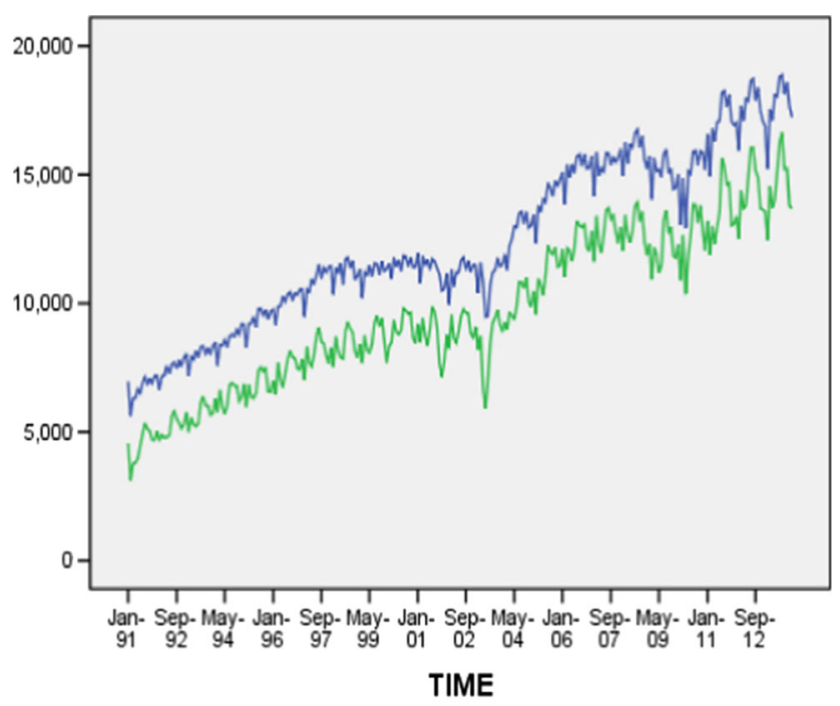

Key: - ASK - RPK

Fig. 2 Time Series Plot of ASK and RPK (in million) of EF flights

$$
\widehat{\Omega}_{i}=\frac{1}{1-\widehat{\rho}_{i}^{2}}\left[\begin{array}{ccccc}
1 & \widehat{\rho}_{i} & \widehat{\rho}_{i}^{2} & \ldots & \widehat{\rho}_{i}^{n-1} \\
\widehat{\rho}_{i} & 1 & \widehat{\rho}_{i} & \ldots & \widehat{\rho}_{i}^{n-2} \\
\widehat{\rho}^{2} & \widehat{\rho} & \ddots & \ldots & \vdots \\
\vdots & \vdots & & 1 & \widehat{\rho}_{i} \\
\widehat{\rho}_{i}^{n-1} & \widehat{\rho}_{i}^{n-2} & \ldots & \widehat{\rho}_{i} & 1
\end{array}\right]
$$

The inverse of the variance covariance matrix can be expressed as:

$$
\begin{gathered}
\widehat{\Omega}_{i}^{-1}=\widehat{\psi}_{i}^{\prime}, \widehat{\psi}_{i} \text { where } \widehat{\rho}_{i}=\frac{\sum_{t=2}^{n} \widehat{\varepsilon}_{i t} \widehat{\varepsilon}_{i t-1}}{\sum_{t=1}^{n} \widehat{\varepsilon}_{i t-1}^{2}} \text { and } \\
\widehat{\psi}_{i}=\left[\begin{array}{ccccc}
\sqrt{1-\widehat{\rho}_{i}^{2}} & 0 & 0 & \cdots & 0 \\
-\widehat{\rho}_{i} & 1 & 0 & \cdots & 0 \\
0 & -\widehat{\rho}_{i} & 1 & \cdots & 0 \\
\vdots & \vdots & \vdots & \ddots & \vdots \\
0 & 0 & 0 & \cdots & 1
\end{array}\right]
\end{gathered}
$$

Step 4: Transform the original trend equation as [2]:

$$
\widehat{\psi}_{i}\left[y_{i t}\right]=\widehat{\psi}_{i}\left[f_{i}\left(t ; \beta_{i}\right)\right]+\widehat{\psi}_{i}\left[\varepsilon_{i t}\right]
$$

where: $\left[y_{i t}\right]$ denotes the vector of stacked output variables $\left[y_{i t}\right]$ for $t=1,2,3, \ldots, T,\left[\varepsilon_{i t}\right]$ is similarly constructed from the error terms and $\left[f_{i}\left(t ; \beta_{i}\right)\right]$ denotes the stacked Regressors vector.

Step 5: Re-estimate model parameters using the data transformed according to Eq. 12.

Step 6: Repeat from Step 1 to Step 5 unless the Ljung-Box test of autocorrelation confirms that there is no serial correlation on the random error terms.

\section{Results and discussions}

\subsection{Assessment of the regional characteristics of load factors}

To construct the best fit of multivariate trend model it is indispensable to follow up the relationship between the flight load factors (LF) for the Europe-Middle East (EM) and the EuropeFar East (EF) with RPK and ASK.

The bootstrap estimates of the results for the RPK and ASK of the EM and EF flights are given in Table 1. From Table 1 we can see that estimates of mean RPK (in million) of the EM and EF flights are 1696.92 (with bias +1.863 ) and 9671.81 (with bias -1.77), respectively. Estimates of mean ASK (in million) of the EM and EF are 2450.76 (with bias +1.53) and 12, 375.32 (with bias +10.46 ), respectively. This result suggests that the EF flights have higher RPK and ASK than the EM flights. Furthermore, the average of 753.84 and $2703.51 \mathrm{ASK}$ (in million) is out of use for every month in the EM and EF flights, respectively. The estimation result of Table 2 shows that in average the EF flights have 7974.89 RPK (in million) and 9924.56 ASK (in million) more than the EM flights. Moreover, the LF of the EF flights is $9.093 \%$ higher than the EM flights.

The evaluation of the results in Table 3 jointly with Fig. 1, and Table 4 jointly with Fig. 2 show that there are strong correlation (coefficients of determination 92.7 and $92.8 \%$, respectively) and positive linear relationships between RPK and ASK in both EM and EF flights. Conferring to the estimation results of Table 3 and Table 4, fit of the linear regression model using the
Table 5 Prais-Winsten recursive parameter estimation of a linear regression of Load Factor (in percentage) in response to RPK (in million)

\begin{tabular}{llclrlll}
\hline Flights & Predictor & Estimators & Std. Error & \multicolumn{1}{c}{ t-cal } & Sig. & R Square & Model Std. Error \\
\hline EM & RPK & 0.02 & 0.001 & 24.852 & 0.0000 & & \\
& Constant & 34.459 & 4.072 & 8.462 & 0.0000 & 0.693 & 2.751 \\
\multirow{2}{*}{ EF } & RPK & 0.003 & 0.000 & 14.059 & 0.0000 & & \\
& Constant & 52.739 & 1.912 & 27.589 & 0.0000 & 0.642 & 2.621 \\
\hline
\end{tabular}




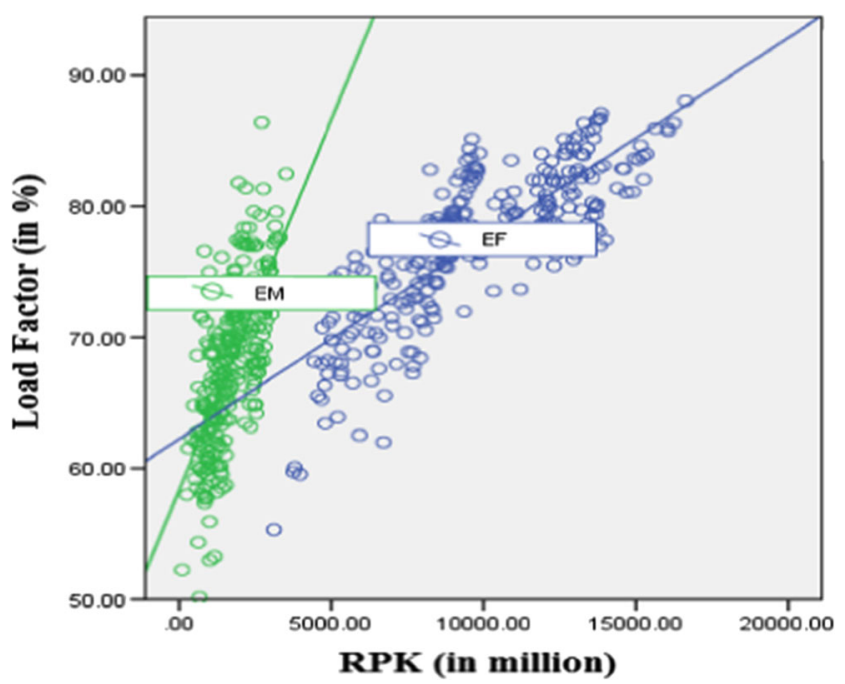

Fig. 3 Scatter Plot of load factor (in \%) versus RPK (in million)

Prais-Winsten recursive parameter estimation indicates that for a million increases in ASK, the RPK for the EM and EF flights is increased by 0.776 and 0.914 million, respectively. This result suggests that managerial decision taken by the airlines to balance supply and demand is generally good for both the EM and EF flights.

Nevertheless, in order to evaluate the airlines managerial capacity in relation to demand and capacity management we need to study the estimation results in Table 5 jointly with Fig. 3. These estimation results show that there exist moderate (coefficients of determination of 69.3 and $64.2 \%$, respectively) and positive linear relationship between LF and RPK in both EM and EF flights. The fit of linear regression using the PraisWinsten recursive parameter estimation indicates that for a million increases in RPK, the LF of the EM and EF flights is increased by 0.02 and $0.03 \%$, respectively. Estimation results from Table 6 jointly with Fig. 4 show that there exist weak (coefficients of determinations of 16.6 and $20.7 \%$ respectively) linear relationships between LF and ASK for both EM and EF flights. Therefore, the closer analysis from Tables 5 and 6 confirm that relatively the airliners have better demand management than capacity management for the EM and EF flights.
4.2 Assessment of the structure of autocorrelation of load factors (LF)

The correct autocorrelation structure for time series analysis is challenging. However, one powerful method for identification is the spectral density analysis. The spectral density is a nonparametric analysis able to give graphical information about how the autocorrelation function behaves in Fourier space.

One of the main graphical methods of spectral density estimation is the response of periodogram for the autocorrelation function frequency of the time series data. This method is extremely sensitive to the optimal autocorrelation structure. Another major method for spectral density estimation is the response of density for the autocorrelation function frequency of the time series data. This method is sensitive to the weighted autocorrelation structure of the data. Therefore, both frequency plots have important information about the autocorrelation structure for the load factor. The result of the nonparametric spectral density estimation and the parametric Ljung-Box test of the load factors of the EM and EF flights is given in Table 7.

The estimation of the periodogram and spectral density for the LF for the EM flights suggests that there exists strong periodic autocorrelation. The periodic autocorrelations are observed after jumping a specific number of months. The yearly repetitive plot of LF of the EM flights over months indicates that there are periodic dependencies. That is the monthly configured patterns for the EM flight's load factor shows some regularity. The smallest LF is observed in May growing until August every year. Once it reaches its peak in August, it starts to decline until November. From November to April the next year the load factor show a stable growth. The cycle stops when the load factor suddenly drops from April to May to find its minimum. The plots for the periodogram and the spectral density suggest that the LF distribution of the EM flight has serial correlation up to a certain number of lags in months. The Ljung-Box test detect that the LF is serially correlated with the order of 15 months and dissipated after 16th month.

The periodogram and the spectral density of the load factor for the EF flights indicate strong periodic autocorrelation. The periodic autocorrelations are observed after a specific number of months. The yearly repetitive
Table 6 Prais-Winsten recursive parameter estimation of a linear regression of Load Factor (in percentage) in response to ASK (in million)

\begin{tabular}{llllllll}
\hline Flights & Predictor & Estimators & Std. Error & t-cal & Sig. & R Square & Model Std. Error \\
\hline EM & ASK & 0.004 & 0.001 & 7.366 & 0.0000 & & \\
& Constant & 57.396 & 1.542 & 37.222 & 0.0000 & 0.166 & 4.254 \\
EF & ASK & 0.001 & 0.000 & 8.443 & 0.0000 & & \\
& Constant & 62.166 & 1.83 & 33.978 & 0.0000 & 0.207 & 3.224 \\
\hline
\end{tabular}




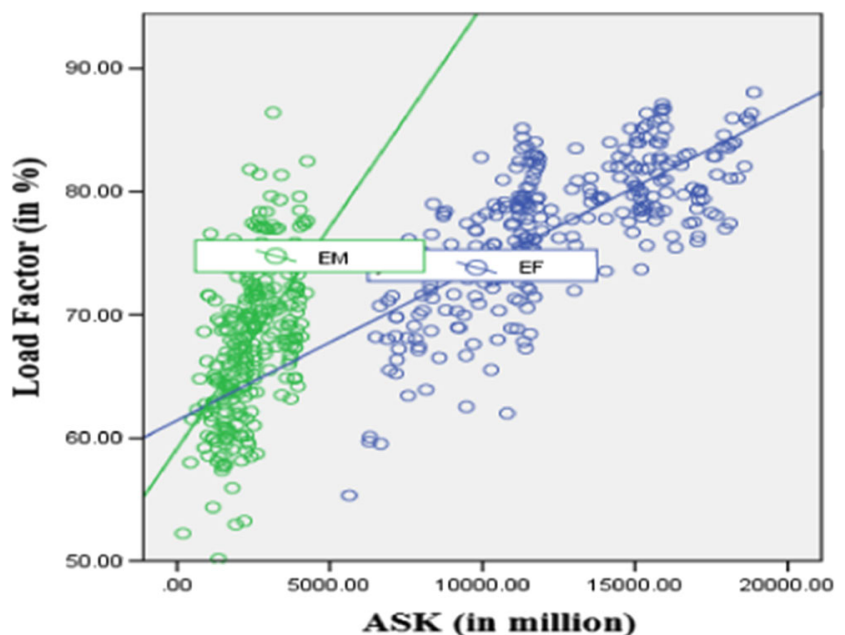

Fig. 4 Scatter Plot of load factor (in \%) ASK (in million)

plot over months suggests that there are strong periodic dependencies. As for the EM flights, the monthlyconfigured patterns of LF of the EF flights show some regularity. As for the EM flights the smallest LF is observed in May growing until August. After reaching its peak in August it starts to decline until December. From December to January the following year the load factor show a growth. The cycle stops when the load factor drops from January to May to find its minimum. The plots of the periodogram and the spectral density suggest that the LF distribution of the EF flight has serial correlation for several months. The Ljung-Box test statistic detects that the LF is serially correlated with the order of 13 months and dissipated after 14th month.

\subsection{Fitting load factors using a multivariate trend model}

The analyses above recognise that both the RPK and ASK for the EF flights are higher than for the EM flights. Similarly, the average LF for the EF flights is higher than for the EM flights. Moreover, above we also found that the LF has different echelons (magnitudes) of linear correlation with RPK for the EM and EF flights. Besides, the analyses prevails that the linear correlation of LF with ASK is weak for both flights. Therefore, using these variables (both RPK and ASK) as common exogenous cohorts for the prediction of the load factor is inappropriate. Therefore, we can explicitly fit the trend model of the EM flight and the EF flight. We are only left with time as a predictor of LF for both flights. Thus, rather than other models, for example panel data regression model, we apply multivariate trend models.

The analyses of the autocorrelation structure have shown that both periodic and serial correlations exist for the LF. More importantly, the structure of autocorrelation is different for two flights. This is showing that

Table 7 The structure of autocorrelation of load factor of EM and EF flights of airlines under the AEA

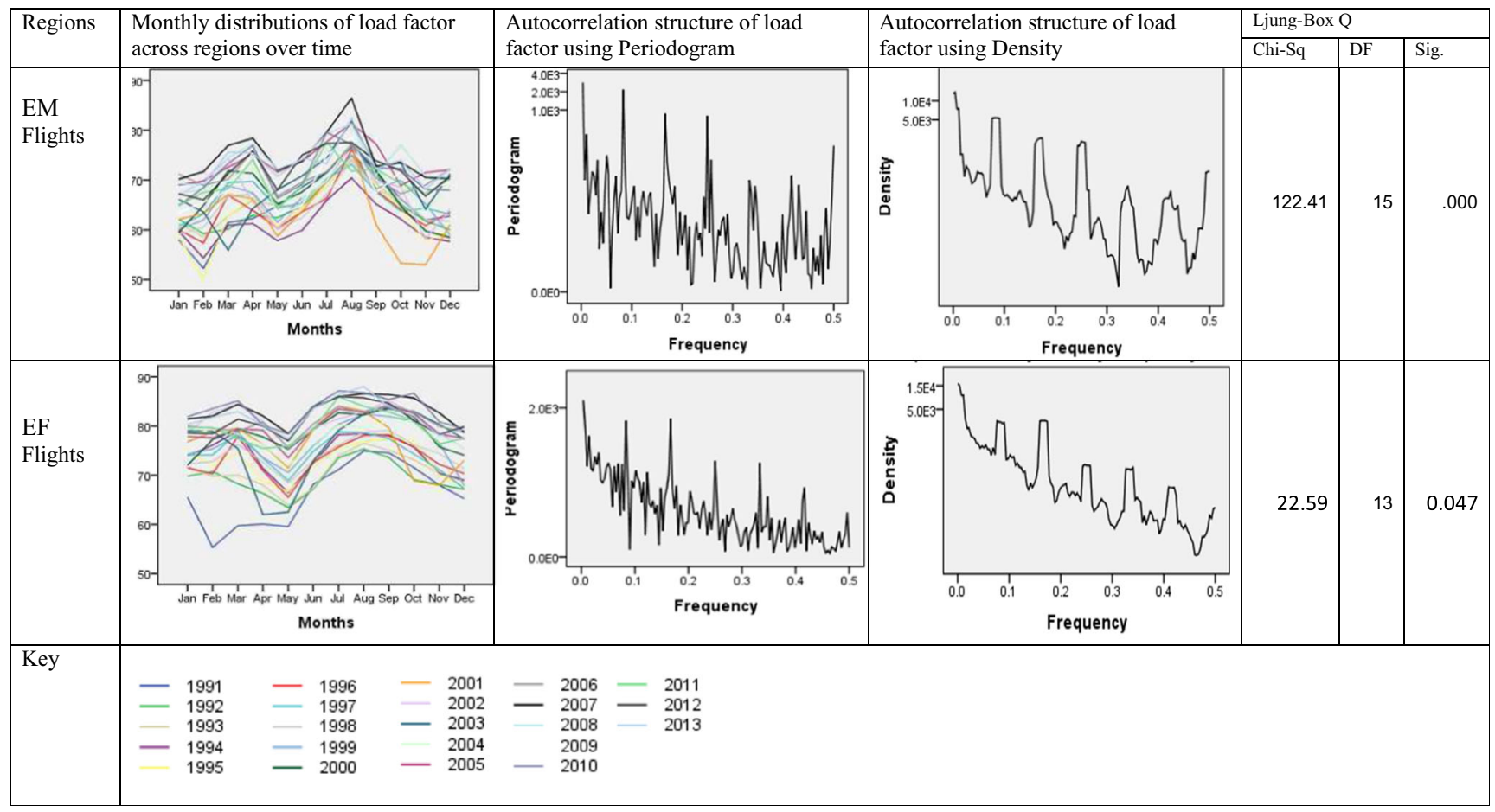


Table 8 The fits of multivariate trend model of the load factor of EM and EF flights

\begin{tabular}{|c|c|c|c|c|c|c|c|c|c|c|}
\hline \multirow[t]{2}{*}{ Parameter Estimates } & \multirow[t]{2}{*}{ Components of $f_{i}\left(t ; \beta_{i}\right)$} & \multirow[t]{2}{*}{ Estimates } & \multirow[t]{2}{*}{ Std. Error } & \multirow[t]{2}{*}{ t-cal } & \multirow{2}{*}{$\begin{array}{l}\text { Approx. } \\
\text { Significance }\end{array}$} & \multirow{2}{*}{$\begin{array}{l}\text { Model Std. } \\
\text { Error }\end{array}$} & \multicolumn{4}{|c|}{ Forecasting of Load factor of 2014 (in \%) } \\
\hline & & & & & & & Month & Expected & LB & UB \\
\hline Rho (AR1-EM) & & 0.47065 & 0.05403 & 8.7109 & 0.00000 & 3.10843 & Jan & 68.48439 & 62.36979 & 74.59898 \\
\hline \multirow[t]{8}{*}{ Time function Coefficients } & $t$ & 0.04047 & 0.00440 & 9.2040 & 0.00000 & & Feb & 70.82609 & 64.7115 & 76.94069 \\
\hline & $\operatorname{Sin}\left(\omega_{2} t\right)$ & -0.89069 & 0.23959 & -3.7176 & 0.00025 & & Mar & 73.48739 & 67.37279 & 79.60199 \\
\hline & $\operatorname{Sin}\left(\omega_{3} t\right)$ & 1.56918 & 0.30565 & 5.1340 & 0.00000 & & Apr & 75.61921 & 69.50461 & 81.7338 \\
\hline & $\operatorname{Sin}\left(\omega_{6} t\right)$ & -2.44483 & 0.41552 & -5.8838 & 0.00000 & & May & 71.20958 & 65.09498 & 77.32418 \\
\hline & $\operatorname{Cos}\left(\omega_{1} t\right)$ & 0.66278 & 0.12738 & 5.2032 & 0.00000 & & Jun & 73.23854 & 67.12394 & 79.35313 \\
\hline & $\operatorname{Cos}\left(\omega_{2} t\right)$ & 2.19048 & 0.23959 & 9.1428 & 0.00000 & & Jul & 78.23464 & 72.12004 & 84.34924 \\
\hline & $\operatorname{Cos}\left(\omega_{3} t\right)$ & -2.05430 & 0.30510 & -6.7332 & 0.00000 & & Aug & 82.73358 & 76.61898 & 88.84817 \\
\hline & $\operatorname{Cos}\left(\omega_{6} t\right)$ & -3.04910 & 0.41357 & -7.3726 & 0.00000 & & Sep & 76.83852 & 70.72392 & 82.95312 \\
\hline \multirow[t]{3}{*}{ Constant of EM Flights } & & 62.35790 & 0.70356 & 88.6320 & 0.00000 & & Oct & 72.66656 & 66.55196 & 78.78115 \\
\hline & & & & & & & Nov & 70.39743 & 64.28283 & 76.51203 \\
\hline & & & & & & & Dec & 71.76413 & 65.64953 & 77.87873 \\
\hline Rho (AR1-EF) & & 0.5381 & 0.0507 & 10.603 & 0.0000 & 2.278 & Jan & 81.15884 & 76.67778 & 85.63989 \\
\hline \multirow[t]{8}{*}{ Time function Coefficients } & $t$ & 0.0250 & 0.0074 & 3.3849 & 0.0008 & & Feb & 84.1656 & 79.68454 & 88.64665 \\
\hline & $\ln (t)$ & 2.4256 & 0.5892 & 4.1171 & 0.0001 & & Mar & 84.06061 & 79.57955 & 88.54167 \\
\hline & $\operatorname{Sin}\left(\omega_{2} t\right)$ & -0.8707 & 0.1710 & -5.093 & 0.0000 & & Apr & 80.45579 & 75.97473 & 84.93685 \\
\hline & $\operatorname{Sin}\left(\omega_{3} t\right)$ & 2.1558 & 0.2242 & 9.6166 & 0.0000 & & May & 78.56003 & 74.07897 & 83.04109 \\
\hline & $\operatorname{Sin}\left(\omega_{6} t\right)$ & -2.4322 & 0.3252 & -7.480 & 0.0000 & & Jun & 81.36409 & 76.88303 & 85.84515 \\
\hline & $\operatorname{Cos}\left(\omega_{2} t\right)$ & -0.3753 & 0.1709 & -2.196 & 0.0289 & & Jul & 85.53465 & 81.05359 & 90.01571 \\
\hline & $\operatorname{Cos}\left(\omega_{3} t\right)$ & -2.1171 & 0.2235 & -9.471 & 0.0000 & & Aug & 87.12244 & 82.64139 & 91.6035 \\
\hline & $\operatorname{Cos}\left(\omega_{4} t\right)$ & 0.7073 & 0.2664 & 2.6552 & 0.0084 & & Sep & 86.38518 & 81.90413 & 90.86624 \\
\hline Constant of EF Flights & & 62.3631 & 1.9255 & 32.387 & 0.0000 & & Oct & 84.91345 & 80.4324 & 89.39451 \\
\hline \multirow{2}{*}{\multicolumn{7}{|c|}{ where: $t=12$ (Current year-1991) + Current month and $\omega_{l}=\frac{\pi}{l}, l=1,2,3 \ldots \ldots$ are periods }} & Nov & 82.93511 & 78.45405 & 87.41616 \\
\hline & & & & & & & Dec & 81.52201 & 77.04095 & 86.00306 \\
\hline
\end{tabular}

the time effect on the LF is not simply fixed or random effects; rather it is dynamic and uniquely associated with the regional flights. Therefore, we will use transcendental time functions as LF predictors to control for periodic autocorrelation in our multivariate trend model. The fit of the multivariate trend model of the LF of the EM and EF flights is given in Table 8. The significance of the harmonic time function confirms the seasonality LF for the EM and EF flights. The significance of time $(t)$ for the fitted model suggests that the LF is improving (growing) with time for both flights. However, the significance of the natural logarithm of time $(\ln (t))$ in the model for the EF flights suggests that the LF performances improvements of the airlines are better for the EF flights than for the EM flights.

In Fig. 5 (left side) we report the comparison of the actual and the predicted values for the load factors. From the Figure we can see that the fit of the multivariate trend model is found to be robust and realistic for the load factor forecast of both flights. Furthermore, in Fig. 5 (right side) we give the plots of the monthly forecasted LF values with upper and lower $95 \%$ prediction intervals for the year 2014.

\section{Conclusions and recommendations}

\subsection{Conclusions}

This study applied advanced econometric analysis on the load factor (LF) of flights of Europe-Middle East (EM) and Europe-Far East (EF) of Association European Airlines (AEA). The econometric analysis provides the following conclusions. The mean RPK for the EM and EF flights are 1696.92 and 9671.81 million, respectively. Likewise, the mean ASK for the EM and EF are 2450.76 and $12,375.32$ million, respectively. Therefore, both in airline transportation demand and capacity the EF flights are higher than for the EM flights. However, the average LF of the EM flights is $9.094 \%$ higher than for the EF flights. 


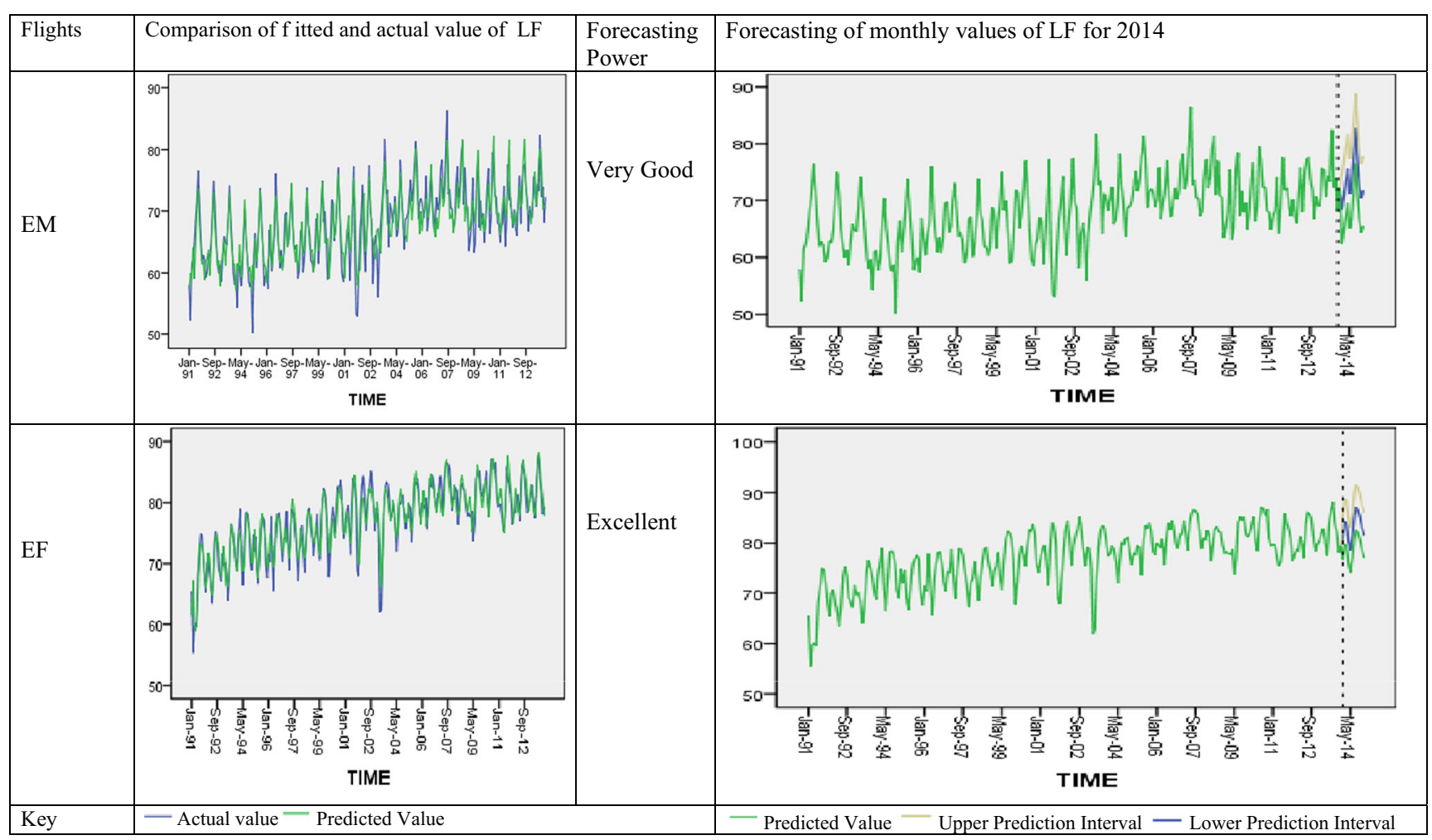

Fig. 5 The comparison of fit of multivariate time trend model with the actual value

The LF for both EM and EF flights are significantly positive correlated with both the RPK and ASK. This generally showed that the airlines have good reaction strategy to their demand. More importantly, we found significant correlation of LF with RPK for the EM and EF flights. However, the significance of correlation of LF with ASK is weak for the EM and EF flights. This confirms that the airlines have better demand than capacity management system for both the EM and the EF flights.

The LF of both EM and EF flights has periodic (season-toseason) correlations. The smallest LF for EM flights is observed in November, December and January then started to grow until July, August and September, and then declining until November. The smallest LF of EF flights is observed in January then it started grow until July, and then declining until December. Furthermore, the LF of both EM and EF flights has serial (month to month) correlations. The LF of EM and EF flights have correlation order of 15 and 13 months, respectively.

Since we have no common exogenous input for the EM and EF flights, we fit multivariate trend model. Using the fitted model we have given forecasted the monthly values for the LF with upper and lower $95 \%$ prediction intervals for 2014.

\subsection{Recommendations and policy implications}

This paper has applied econometric models to analyse the LF of EM and EF flights of airlines of the AEA.
Our results have important managerial policy implications and may suggest the following policy recommendations. Fit of the LF using the multivariate time series model is found more robust and realistic. The AEA may therefore use the model for prediction of the LF for the distribution of relevant flights. Hence, it is recommended that the AEA apply the model to regional flights. In the airline industry, in addition to decreasing the airlines cost, the profitability of a given airline is dependent on the joint maximization of yield and LF. In order to push up the LF and the yield simultaneously, and to produce strategic decisions about the profitability of airlines, the AEA may extend the LF analysis to individual airlines. The outcome of such analysis will give rigorous information about the LF. Consequently, the AEA will have quantitative input on how to restructure the yield management, network design, etc. with respect of specific flights over time. The econometric analysis have identified that the demand management of the airlines is better than the capacity management. In this regard, the AEA is recommended to keep up with the existing demand management strategy and improvement is needed on the strategy of capacity management. Finally, as suggested by many international industry studies, the airline industry is seasonal. In this paper, we find that the LF of the EM and EF flights are both seasonal and differ between flights. The result implies that the LF is far from stable and 
stabilizing policies by airlines has so far not been successful. The AEA may therefore continuously focus on the stabilisation and the improvement of the LF for the industry.

Acknowledgments First of all we have ultimate thank for God, who gave us space to live and time to think. Secondly, we would like to thank all the members of the Made University College. Finally, we want to thank all the scholars referenced in the paper.

Open Access This article is distributed under the terms of the Creative Commons Attribution License which permits any use, distribution and reproduction in any medium, provided the original author(s) and source are credited.

\section{References}

1. Amemiya T (1985) Advanced econometrics. Harvard University Press, Cambridge

2. Baltagi BH (2008) Econometric analysis of panel data, 4th edn. John Wiley \& Sons, Chichester

3. Boashash B (2003) Time-frequency signal analysis and processing: a comprehensive reference. Elsevier Science, Oxford

4. Brueckner JK, Whalen WT (2000) The price effects of international airlinealliances. Journal of Law and Economics 43:503-545

5. Chan J, Koop G, Leon-Gonzales R, Strachan R (2012) Time varying dimension models. J Bus Econ Stat Vol 30

6. Cochran WG, Cox GM (1992) Experimental designs, 2nd edn. Wiley, New York

7. Cook RD, Weisberg S (1982) Residuals and influence in regression, Reprth edn. Chapman and Hall, New York

8. Cross RG (1997) Revenue management: hard-core tactics for market domination. Broadway Books, New York

9. Cross R, Higbie J, Cross Z (2010) Milestones in the application of analytical pricing and revenue management. J Rev Pricing Manag 10: 8-18

10. Davidson J (2000) Econometric theory. Blackwell Publishing, Oxford, UK

11. Davidson R, Mackinnon JG (1993) Estimation and inference in econometrics. Oxford University Press, Oxford

12. Davies A, Lahiri K (1995) A new framework for testing rationality and measuring aggregate shocks using panel data. Journal of Econometrics 68:205-227

13. Davison AC, Hinkley DV (1997) Bootstrap methods and their applications. Cambridge University Press, Cambridge

14. Distexhe V, Perelman S (1994) Technical efficiency and productivity growth in an era of deregulation: the case of airlines. Revue Suisse d'Economie Politique 130(4):669-689

15. Doganis R (2010) Flying off course, airline economics and marketing, 4th edn. Routledge, LonMAn and New York

16. Engelberg S (2008) Digital signal processing: an experimental approach. Springer, ISBN 978-1-84800-118-3

17. Fahrmeir L, Kneib T, Lang S (2009) Regression. Model and method, 2nd edn. Springer, Heidelberg
18. Flores-Fillol R, Moner-Colonques R (2007) Strategic formation of airline alliances. Journal of Transport Economics and Policy 41(3): 427-449

19. Frees E (2004) Longitudinal and panel data: analysis and applications in the social sciences. Cambridge University Press, New York

20. Hamilton JD (1994) Time series analysis. Princeton University Press

21. ICAO (2013) Airport Economics Manual: Retrieved on 21 April 2014 at: www.icao.int/sustainability/MAcuments/MAc9562 en.pdf

22. Kahn AE (1988) Surprises of deregulation. The American Economic Review 78(2):316-322, JSTOR

23. Kammler D (2000) A first course in Fourier analysis. Prentice Hall, Upper Saddle River

24. Karagiannis E, Kovacevic M (2000) A method to calculate the jackknife variance estimator for the Gini coefficient. Oxford Bulletin of Economics and Statistics 62:119-122

25. Kaul S (2009) Yield management: getting more out of what you already have. Ericsson Business Review, No. 2: 17-19

26. Link H (2004) PEP-a yield-management scheme for rail passenger fares in Germany. Japan Railway \& Transport Review 38:54

27. Kellner L (2000) Building a global airline brand, 2000 Transport Conference. UBS Warburg, London

28. Luc B, Lubrano M, Jean-François R (2000) Bayesian Inference in Dynamic Econometric Models Oxford Scholarship Online: October 2011

29. Lütkepohl H (2006) New introduction to multiple time series analysis. Springer, Berlin

30. Marriott JJ, Cross RG (2000) Room at the revenue inn. In: Krass $P$ (ed) Book of management WisMAm: classic writings by legendary managers. Wiley, New York, pp 199-208

31. McGill J, Van Ryzin G (1999) Revenue management: research overview and prospects. Transportation Science 33:233-256

32. Minho C, Ming Fan, Yong-Pin Z (2007) An Empirical Study of Revenue Management Practices in the Airline Industry, Michael G. Foster School of Business University of Washington

33. Netessine S, Shumsky R (2002). Introduction to the Theory and Practice of Yield Management. INFORMS Trans Educ 3:(1)

34. Prais SJ, Winsten CB (1954) Trend estimators and serial correlation. Cowles Commission, Chicago

35. Priestley MB (1991) Spectral analysis and time series. Academic, New York

36. Stoica P, Moses R (2005) Spectral analysis of signals. Prentice Hall, Upper Saddle River, 07458

37. Talluri KT, Van Ryzin GJ (2001) Revenue management under a general discrete choice model of consumer behavior. Manag Sci

38. Talluri KT, Van Ryzin GJ (2004) The theory and practice of revenue management. Kluwer Academic Publishers, Norwell, Massachusettes

39. Kailath T, Sayed AH, Babak H (2000) Linear Estimation. PrenticeHall

40. Van Dender K (2007) Determinants of fares and operating revenues at US airports. J Urban Econ 62:317-336

41. Vassilis AH (2008) Computational methods in econometrics. The New Palgrave Dictionary of Economics, 2nd Edn

42. Verbeek M (2004) A guide to modern econometrics, 2nd edn. John Wiley \& Sons, Chichester

43. Weisberg S (1985) Applied linear regression, 2nd edn. Wiley, New York

44. Wooldridge JM (2013) Introductory econometrics: a modern approach (5th international ed). Australia: South Western 